\title{
Antimalarial activity of betulinic acid and derivatives in vitro against Plasmodium falciparum and in vivo in $P$. berghei-infected mice
}

\author{
Matheus Santos de Sá • José Fernando Oliveira Costa • \\ Antoniana Ursine Krettli • Mariano Gustavo Zalis • \\ Gabriela Lemos de Azevedo Maia • Ivana Maria Fechine Sette • \\ Celso de Amorim Câmara • José Maria Barbosa Filho • \\ Ana Maria Giulietti-Harley • Ricardo Ribeiro dos Santos • \\ Milena Botelho Pereira Soares
}

Received: 9 September 2008 / Accepted: 3 March 2009/Published online: 15 April 2009

(C) Springer-Verlag 2009

\begin{abstract}
Malaria is one of the most important tropical diseases and mainly affects populations living in developing countries. Reduced sensitivity of Plasmodium sp. to formerly recommended antimalarial drugs places an increasing burden on malaria control programs as well as on national health systems in endemic countries. The present study aims to evaluate the antimalarial activity of betulinic acid and its derivative compounds, betulonic acid, betulinic acid acetate, betulinic acid methyl ester, and betulinic acid methyl ester acetate. These substances showed antiplasmodial activity against chloroquineresistant Plasmodium falciparum parasites in vitro, with $\mathrm{IC}_{50}$ values of $9.89,10.01,5.99,51.58$, and $45.79 \mu \mathrm{M}$, respectively. Mice infected with Plasmodium berghei and treated with betulinic acid acetate had a dose-dependent
\end{abstract}

M. S. de Sá · J. F. O. Costa • R. Ribeiro dos Santos •

M. B. P. Soares

Centro de Pesquisas Gonçalo Moniz,

Fundação Oswaldo Cruz,

Salvador, Bahia, Brazil

\section{A. U. Krettli}

Centro de Pesquisas René Rachou, Fundação Oswaldo Cruz,

Belo Horizonte, Minas Gerais, Brazil

M. G. Zalis

Hospital Universitário Clementino Fraga Filho,

Universidade Federal do Rio de Janeiro,

Rio de Janeiro, Rio de Janeiro, Brazil

G. L. d. Maia $\cdot$ J. M. B. Filho

Universidade Federal da Paraíba,

João Pessoa, Paraíba, Brazil reduction of parasitemia. Our results indicate that betulinic acid and its derivative compounds are candidates for the development of new antimalarial drugs.

\section{Introduction}

Malaria is one of the most important tropical diseases due to its high morbidity and mortality rates, affecting over two billion people in endemic countries. In a public health problem in countries where transmission occurs regularly, this disease mainly afflicts populations living in developing countries, constituting an obstacle to the efforts toward economic development (WHO 2005).

\section{M. F. Sette \\ Universidade Estadual da Paraíba, \\ Campina Grande, Paraíba, Brazil \\ C. d. Câmara \\ Universidade Federal Rural de Pernambuco, \\ Recife, Pernambuco, Brazil}

A. M. Giulietti-Harley

Universidade Estadual de Feira de Santana,

Feira de Santana, Bahia, Brazil

M. B. P. Soares $(\bowtie)$

Laboratório de Engenharia Tecidual e Imunofarmacologia,

Centro de Pesquisas Gonçalo Moniz, Fundação Oswaldo Cruz,

Rua Waldemar Falcão, 121, Candeal,

40296-710 Salvador, Bahia, Brazil

e-mail: milena@bahia.fiocruz.br 
The causative parasite of the malignant form of malaria, Plasmodium falciparum, frequently presents resistance to chloroquine, the cheapest and most utilized antimalarial drug (WHO 2008). Another problem concerning drug resistance in $P$. falciparum is the occurrence of crossresistance among drugs belonging to the same chemical family (WHO 2001). Drug resistance plays an important role in the occurrence and severity of epidemic diseases in the world (Majori 2004). Moreover, there is a great disparity between the public health importance of tropical diseases, such as malaria, and the amount of resources invested in the development of new drugs to combat these diseases (WHO 2001).

As a consequence of drug resistance, drugs like quinine, chloroquine, primaquine, and mefloquine are ineffective in treating malaria in many endemic regions of the world (Schlitzer 2007). Thus, the development of new antimalarial pharmacotherapy is necessary. Many different classes of natural products, such as terpenes (Meshnick 2002), flavonoids (Auffret 2007; Froelich et al. 2007), and alkaloids (Chea et al. 2007), have been studied regarding antimalarial activity. This study aimed at evaluating the antimalarial activity of betulinic acid and its derivatives against chloroquine-resistant $P$. falciparum parasites in vitro and Plasmodium berghei parasites in vivo.

\section{Materials and methods}

Purification of betulinic acid and synthesis of derivatives

Betulinic acid was isolated from Zizyphus joazeiro Mart. (Rhamnaceae) (Barbosa-Filho et al. 1985). The derivatives were obtained by standard and straightforward chemical procedures already related in literature. The betulinic acid acetate was obtained by the acetylation reaction of betulinic acid with an acetic anhydride/pyridine mixture (Kim et al. 2001). Betulonic acid was obtained in the chromic acid oxidation from betulinic acid (Urban et al. 2007). The treatment of betulinic acid and the betulinic acid acetate with excess ethereal diazomethane solution rendered the corresponding methyl ester and derivatives (Urban et al. 2005; Uzenkova et al. 2005). All compounds were purified by column chromatography and showed ${ }^{1} \mathrm{HNMR}$ and ${ }^{13} \mathrm{CNMR}$ spectra in accordance with literature previously cited.

The structures of betulinic acid and its derivatives used in this study are shown in Fig. 1.

\section{Cytotoxicity assay}

To determine the cytotoxicity of betulinic acid (BA) and the derivative compounds betulonic acid (BOA), betulinic acid acetate (BAA), betulinic acid methyl ester (BAME), and betulinic acid methyl ester acetate (BAMEA), BALB/c mice splenocytes were cultured in 96-well plate $(6 \times$ $10^{5}$ cells/well) in Dulbecco's modified Eagle's medium (Sigma Chemical Co., St. Louis, MO, USA) supplemented with 10\% fetal calf serum (Cultilab, Campinas, São Paulo, Brazil) and $50 \mu \mathrm{g} / \mathrm{ml}$ of gentamycin (Novafarma, Anapolis, Goiás, Brazil). The pure substances were tested in five concentrations, in triplicates. One microCi/well $\left[\right.$ methyl $\left.-{ }^{3} \mathrm{H}\right]-$ thymidine (Amersham, Little Chalfont, England) was added to the cultures which were incubated during $24 \mathrm{~h}$ at $37^{\circ} \mathrm{C}$ and $5 \% \mathrm{CO}_{2}$. After this period, plates were harvested using a cell harvester (MPXRI 96TI, Brandel, Gaithersburg, MD, USA) to determine the ${ }^{3} \mathrm{H}$-thymidine incorporation using a $\beta$-radiation counter (Multilabel Reader, Hidex, Turku, Finland). The viability of the cells was determined by ${ }^{3} \mathrm{H}$ thymidine incorporation and the cytotoxicity was calculated in relation to the ${ }^{3} \mathrm{H}$-thymidine incorporation of untreated cultures.

Anti-P. falciparum in vitro assay

Betulinic acid and the derivative compounds were tested for antimalarial activity in vitro using the $P$. falciparum W2 clone, which is chloroquine resistant and mefloquine sensitive (Junior 1999). All the parasites were maintained in continuous culture of human erythrocytes (blood group $\mathrm{A}^{+}$) using Rapid Prototyping and Manufacturing Institute (RPMI) medium supplemented with $10 \%$ human plasma (Trager and Jensen 2005).

Parasites grown at $1 \%$ to $2 \%$ parasitemia and $2.5 \%$ hematocrit were incubated with the pure substances tested at various concentrations, diluted with $4 \%$ dimethyl sulfoxide (DMSO) in culture medium (RPMI 1640) without

Fig. 1 Structures of betulinic acid and derivatives

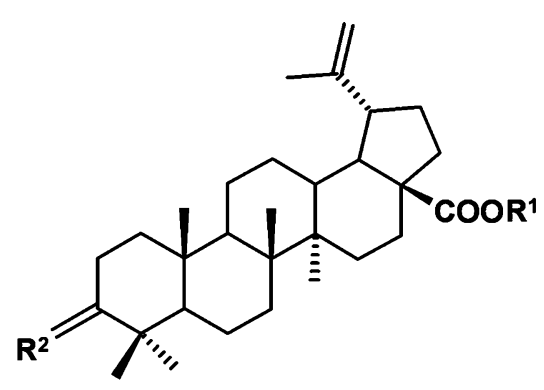


hypoxanthine. Mefloquine was used in each experiment as a control for $P$. falciparum drug response. Cultures containing parasites were harvested using a cell harvester to evaluate the ${ }^{3}[\mathrm{H}]$-hypoxanthine incorporation in a $\beta$ radiation counter. Inhibition of parasite growth was evaluated by comparison with ${ }^{3}[\mathrm{H}]$-hypoxanthine uptake in drug-treated versus untreated wells. All the assays were performed in triplicates as described previously (AndradeNeto et al. 2004; Zalis et al. 1998).

Assessment of antimalarial activity

The antimalarial activity of betulinic acid acetate was evaluated in mice infected with $P$. berghei, strain NK65 (Andrade et al. 2007). Parasites were maintained by weekly blood passage $10^{6}$ infected red blood cells per mouse by intraperitoneal (i.p.) route. The animals were randomly sorted into groups of five and treatment was administered daily, during four consecutive days, beginning on the first day of infection. BAA was suspended in saline solution plus $10 \%$ DMSO immediately before use in doses of 10, 50, and $100 \mathrm{mg} / \mathrm{kg}$. Each mouse received $200 \mu \mathrm{l}$, by oral or by intraperitoneal route. Experiments included a control group treated with the standard antimalarial drug chloroquine at $50 \mathrm{mg} / \mathrm{kg}$ and a mock-treated group (10\% DMSO in saline). The antimalarial activity was evaluated by counting parasitemia in blood smears at days 4 and 7 after parasite inoculation, by optical microscopy, after fixation with methanol and staining with fast panoptic (Laborclin, Pinhais, Brazil). Inhibition of parasite growth in drug-treated groups was calculated in relation to the control (mice treated with saline solution plus $10 \%$ DMSO) group. The results were expressed as the percentage of parasitemia reduction.

$\mathrm{IC}_{50}$ and $\mathrm{LC}_{50}$ calculations and statistical analyses

The lethal concentration of $50 \%$ of BALB/c mice splenocytes $\left(\mathrm{LC}_{50}\right)$ and the inhibitory concentration of $50 \%\left(\mathrm{IC}_{50}\right)$ of $P$. falciparum were calculated based on a nonlinear regression (curve fit). The statistical analyses were made by one-way analysis of variance and Newman-Keuls multiple comparison tests using Graph Pad Prism version 4.0 (Graph Pad Software, San Diego, CA, USA). Differences were considered significant when $p$ values were $<0.05$.

Calculation of the selectivity index

The selectivity index (SI) was defined by calculating the value of $\mathrm{LC}_{50}$ versus $\mathrm{IC}_{50}$ (Bézivin et al. 2003). The SI was considered as significant for values higher than three.

\section{Results}

Cytotoxicity of betulinic acid and derivatives

In order to determine the cytotoxic potential of the compounds studied, BA, BOA, BAA, BAME, and BAMEA were tested in five different concentrations. As shown in Table 1, all substances had lower cytotoxicity compared to mefloquine, used as the standard antimalarial drug. BOA was the compound with lower cytotoxicity (higher $\mathrm{LC}_{50}$ value) when compared to the other substances tested, while BAMEA was the most toxic.

In vitro antimalarial activity

To assess the antimalarial activity of the compounds, BA and its derivatives were first assayed in vitro against W2 strain of $P$. falciparum. BA and its derivative compounds BOA and BAA had antiplasmodial activity, with $\mathrm{IC}_{50}$ values below $10 \mu \mathrm{M}$, whereas BAME and BAMEA presented $\mathrm{IC}_{50}$ values above $45 \mu \mathrm{M}$ (Table 1). Mefloquine had an $\mathrm{IC}_{50}=0.04 \mu \mathrm{M}$ against this strain of $P$. falciparum, a result similar to that described before for an inoculum of $1 \%$ to $2 \%$ parasitemia and $2.5 \%$ hematocrit (Andrade-Neto

Table 1 Anti-P. falciparum activity and in vitro cytotoxicity of betulinic acid and derivative compounds

\begin{tabular}{|c|c|c|c|c|}
\hline Substance & Yield $(\%)^{\mathrm{a}}$ & $\mathrm{IC}_{50}(\mu \mathrm{M})$ & $\mathrm{LC}_{50}(\mu \mathrm{M})$ & SI \\
\hline BA & 90.65 & $9.89 \pm 0.52$ & $62.36 \pm 32.67 *$ & 6.3 \\
\hline BOA & 93.28 & $10.01 \pm 1.29$ & $96.10 \pm 8.52 *$ & 9.6 \\
\hline BAA & 95.08 & $5.99 \pm 0.06$ & $21.98 \pm 2.71$ & 3.7 \\
\hline BAME & 93.74 & $51.58 \pm 10.85^{*}$ & $83.21 \pm 6.46^{*}$ & 1.6 \\
\hline BAMEA & 60.33 & $45.79 \pm 36.26^{*}$ & $15.42 \pm 19.30$ & 0.3 \\
\hline Mefloquine & 91.69 & $0.04 \pm 0.01$ & $9.53 \pm 0.46$ & 238 \\
\hline
\end{tabular}

Values are mean \pm standard deviation of three independent experiments

$S I$ selectivity index

$* P<0.01$ compared to control

${ }^{\mathrm{a}}$ The maximal concentration of BAA and derivatives tested was $100 \mu \mathrm{g} / \mathrm{ml}$ and of mefloquine was $0.25 \mu \mathrm{g} / \mathrm{ml}$ 
Fig. 2 Parasitemia of $P$. berghei-infected mice treated with $10 \%$ DMSO in saline (mock), BAA at 10, 50, and $100 \mathrm{mg} / \mathrm{kg}$, or chloroquine at $50 \mathrm{mg} / \mathrm{kg}$, by oral $(A)$ or intraperitoneal $(B)$ routes, daily, for four consecutive days. Blood parasitemia was determined on several days after infection. Values represent the means \pm standard error of five mice per group in one experiment of two performed a

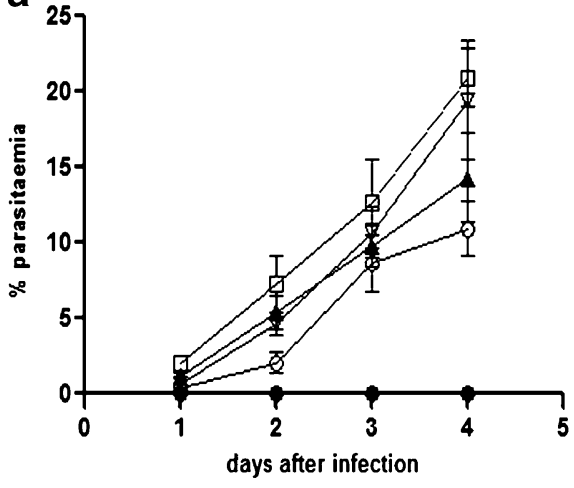

b

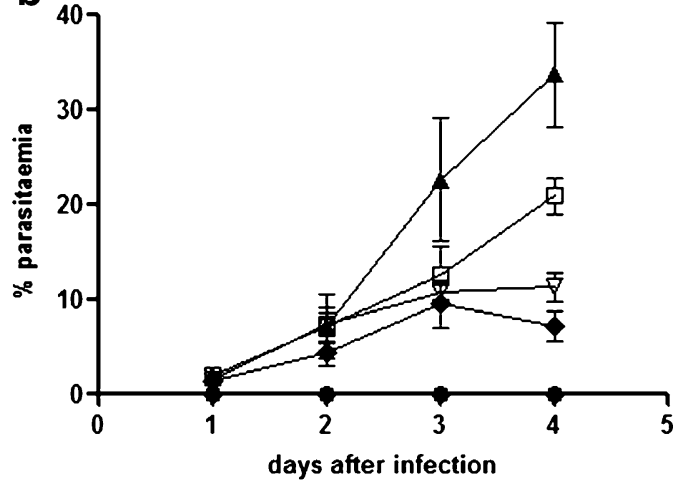

七 MOCK \& BAA $10 \mathrm{mg} / \mathrm{kg} \rightarrow$ BAA $50 \mathrm{mg} / \mathrm{kg}$

BAA $100 \mathrm{mg} / \mathrm{kg} \multimap$ Chloroquine $50 \mathrm{mg} / \mathrm{kg}$

et al. 2004). The analysis of the selectivity index (SI) showed that BAA was the compound with higher SI, whereas BAMEA had the lowest SI (Table 1). The SI index of mefloquine, however, was significantly higher than the one found for BAA.

In vivo antimalarial activity of BAA

Since BAA was the compound with best SI, we decided to test its antimalarial activity in vivo in $P$. berghei-infected mice. Treatment with BAA by oral route did not alter the levels of parasitemia in mice infected with $P$. berghei compared to mice treated with saline solution plus $10 \%$ DMSO (Fig. 2a). In contrast, the administration of BAA by i.p. route caused a dose-dependent reduction of parasitemia of at least $70 \%$ on the seventh day following infection (Fig. 2b). Mice treated with chloroquine, a standard antimalarial drug, had undetectable parasitemia (Fig. 2a, b).

Treatment with BAA i.p. increased the survival of $P$. berghei-infected mice at a dose of $100 \mathrm{mg} / \mathrm{kg}$ at least until day 21 postinfection. Treatment with BAA in doses of 10 and $50 \mathrm{mg} / \mathrm{kg}$, however, did not affect the mortality rate of $P$. berghei-infected mice, which started to die by day 10 , similar to control mice. All the mice in the chloroquinetreated group survived during the experiment (Fig. 3).

\section{Discussion}

In this study, we demonstrated that betulinic acid and the derivative compounds BOA and BAA have a significant antimalarial activity in vitro against $P$. falciparum chloroquine resistant (W2 strain). In addition, we showed that BAA, the most active anti-Plasmodium substance tested, has antimalarial activity in vivo.

The $\mathrm{IC}_{50}$ of mefloquine against $P$. falciparum is about 150 times lower than that of BAA, the most active betulinic acid derivative in vitro. On the other hand, this drug was more toxic than $\mathrm{BAA}$, with $\mathrm{LC}_{50}$ two times lower than BAA. It is important to say that selectivity index is an important parameter to evaluate the potential of the drugs tested, and a SI value $>3$ indicates high selectivity (Prayong et al. 2008). BAA present a SI value of 3.7 which mefloquine SI was 238. Although mefloquine SI was 64 times higher than BAA SI, this drug may serve as basis for the development of new malaria pharmacotherapies able to control mefloquine-resistant parasites.
Fig. 3 Cumulative mortality rates of $P$. berghei-infected mice treated with $10 \%$ DMSO in saline (mock), BAA at 10, 50, and $100 \mathrm{mg} / \mathrm{kg}$, or chloroquine at $50 \mathrm{mg} / \mathrm{kg}$, by intraperitoneal route, daily, for four consecutive days. Mortality was evaluated several days after infection. Results are from one experiment done with five mice per group of two performed

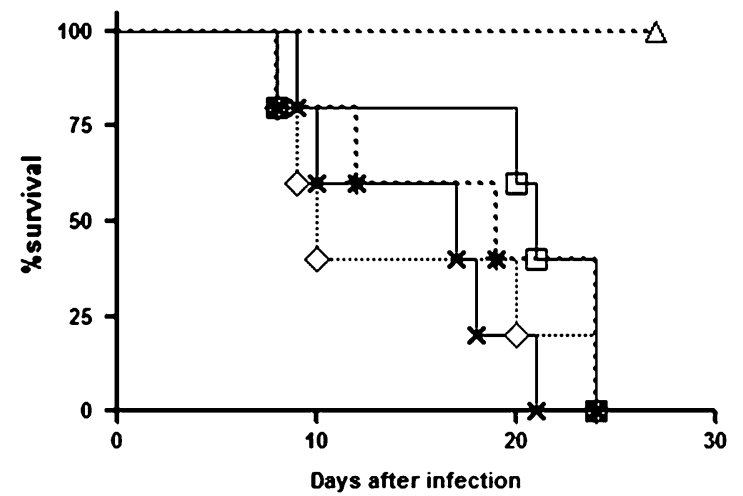


The identification of new molecular targets in Plasmodium sp. may aid the design of compounds with selective activity during the process of drug development. The investigation of the mechanisms of action of BAA may help the identification of new molecular targets. With this regard, it has been suggested before that BA inhibits topoisomerases (Wada et al. 2005). Thus, BAA may also act by inhibiting topoisomerases from Plasmodium sp., a possibility that we are currently investigating.

BAA was also active in vivo when administrated to $P$. berguei-infected mice by intraperitoneal route, although it did not cause a reduction of parasitemia when used by oral route. This result may be attributed to a slow absorption of the compound, to the high metabolism rate of the mouse model, or to retention of the compound as lipid-bound complexes due to its lipophilic nature. These factors could lead to low bioavailability of the drug at the target site of action, the intracellular parasite.

A previous report has shown that treatment of $P$. berghei-infected mice with betulinic acid by intraperitoneal route did not cause a reduction of parasitemia (Steele et al. 1999). Our finding that the derivative betulinic acid acetate has in vivo activity suggests that the structural changes in the molecule significantly alter the anti-Plasmodium activity. Further studies to explore this compound as a prototype for an antimalarial drug should be carried out, especially aiming at the $P$. falciparum chloroquine-resistant parasites, which are rather frequent worldwide.

Acknowledgments The authors wish to thank Fabrício Souza Silva for technical assistance. The experiments made in this study comply with the current laws of the Brazil. The approval for this work was obtained from the Ethics Committee on the Use of Laboratorial Animals (reference number 004/2002). This work received financial support from FIOCRUZ, RENORBIO, CNPq, FINEP, MCT, and INSEAR.

\section{References}

Andrade AA, de Pilla Varotti L, de Freitas IO, de Souza MV, Vasconcelos TR, Boechat N, Krettli AU (2007) Enhanced activity of mefloquine and artesunic acid against Plasmodium falciparum in vitro and Plasmodium berghei in mice by combination with ciprofloxacin. Eur J Pharmacol 558:194-198

Andrade-Neto VF, Goulart MOF, Filho JFS, Silva MJ, Pinto MCFR, Pinto AV, Zalis MG, Carvalho LH, Krettli AU (2004) Antimalarial activity of phenazines from lapachol, $\beta$-lapachone and its derivatives against Plasmodium falciparum in vitro and Plasmodium berghei in vivo. Bioorg Med Chem Lett 14:1145-1149

Auffret G, Labaied M, Frappier F, Rasoanaivo P, Grellier P, Lewin G (2007) Synthesis and antimalarial evaluation of a series of piperazinyl flavones. Bioorg Med Chem Lett 15:959-963
Barbosa-Filho JM, Trigueiro JA, Cheriyan UO, Bhattacharyya J (1985) Constituents of the stem-bark of Zizyphus joazeiro. J Nat Prod 48:152-153

Bézivin C, Tomasi S, Lohézic-Le Dévéhat F, Boustie J (2003) Cytotoxic activity of some lichen extracts on murine and human cancer cell lines. Phytomed 10:499-503

Chea A, Hout S, Bun SS, Tabatadze N, Gasquet M, Azas N, Elias R, Balansard G (2007) Antimalarial activity of alkaloids isolated from Stephania rotunda. J Ethnopharmacol 30:132-137

Froelich S, Onegi B, Kakooko A, Siems K, Schubert C, Jenett-Siems K (2007) Plants traditionally used against malaria: phytochemical and pharmacological investigation of Momordica foetida. Braz J Pharmacogn 17:1-7

Junior CC, Marques C, Alencar FEC, Durlacher RR, Alween A, Segurado AAC, Pang LW, Zalis MG (1999) Antimalarial drug susceptibility testing of plasmodium falciparum in Brazil using a radioisotope method. Mem Inst Oswaldo Cruz 94:803-809

Kim JY, Koo HM, Kim DSHL (2001) Development of C-20 modified betulinic acid derivatives as antitumor agents. Bioorg Med Chem Lett 11:2405-2408

Majori G (2004) Combined antimalarial therapy using artemisinin. Parassitologia 46:85-87

Meshnick SR (2002) Artemisinin: mechanisms of action, resistance and toxicity. Int J Par 32:1655-1660

Prayong P, Barusrux S, Weerapreeyakul N (2008) Cytotoxic activity screening of some indigenous Thai plants. Fitoter 79:598-601

Schlitzer M (2007) Malaria chemotherapeutics part I: history of antimalarial drug development, currently used therapeutics and drugs in clinical development. Chem Enab Drug Disc 7:944986

Steele JC, Warhurst DC, Kirby GC, Simmonds MS (1999) In vitro and in vivo evaluation of betulinic acid as an antimalarial. Phytother Res 13:115-119

Trager W, Jensen JB (2005) Human malaria parasites in continuous culture. J Parasitol 91:484-486

Urban M, Sarek J, Tislerova I, Dzubak P, Hajduch M (2005) Influence of esterification and modification of A-ring in a group of lupane acids on their cytotoxicity. Bioorg Med Chem 13:5527-5535

Urban M, Sarek J, Kvasnica M, Tislerova I, Hajduch M (2007) Triterpenoid pyrazines and benzopyrazines with cytotoxic activity. J Nat Prod 70:526-532

Uzenkova NV, Petrenko NI, Shakirov MM, Shul'ts EE, Tolstikov GA (2005) Synthesis of 30-amino derivatives of lupane triterpenoids. Chem Nat Compounds 41:692-700

Wada S, Tanaka R (2005) Betulinic acid and its derivatives, potent DNA topoisomerase II inhibitors, from the bark of Bischofia javanica. Chem Biodivers 2:689-694

WHO (2001) Drug resistance in malaria. WHO/CDS/CSR/DRS/ 2001.4 Geneva

WHO (2005) Global malaria situation. World Health Organization. World malaria report Geneva. http://whqlibdoc.who.int/publications/2005/ 9241593199_section1_eng.pdf[accesses 28 July 2008]

WHO (2008) The use of antimalarial drugs. Part I: policy implications. Current status of antimalarial drug resistance. World Health Organization, Geneva. http://www.who.int/malaria/cmc_upload/ 0/000/014/923/am_toc.htm[accesses 27 July 2008].

Zalis MG, Pang L, Silveira MS, Milhous WK, Wirth DF (1998) Characterization of Plasmodium falciparum isolated from the Amazon region of Brazil: evidence for quinine resistance. Am J Trop Med Hyg 58:630-637 